\title{
Immune Checkpoint Inhibitor Related Neuropathic Adverse Effects on Cancer Patients
}

\author{
Samrat Khanal, Haijun Zhang* \\ Department of Oncology, Zhongda Hospital, Medical School, Southeast University, Nanjing, China \\ Email: *haijunzhang@seu.edu.cn
}

How to cite this paper: Khanal, S. and Zhang, H.J. (2019) Immune Checkpoint Inhibitor Related Neuropathic Adverse Effects on Cancer Patients. Journal of Biosciences and Medicines, 7, 1-12. https://doi.org/10.4236/jbm.2019.76001

Received: April 8, 2019

Accepted: May 28, 2019

Published: May 31, 2019

Copyright $\odot 2019$ by author(s) and Scientific Research Publishing Inc. This work is licensed under the Creative Commons Attribution International License (CC BY 4.0).

http://creativecommons.org/licenses/by/4.0/

(c) (i) Open Access

\begin{abstract}
With the recent development and clinical application, immune checkpoint inhibitors (ICIs) intervention is being increasingly common for multiple malignancies. With these, prospect on focus creates an increasing necessity for an early recognition with proper documentation of upcoming treatment-related toxicities. These treatment-related toxicities are generally termed as immune-related adverse effects (irAEs) [1]. It is a known fact that the upregulation of T-cell initiates autoimmunity resulting in these irAEs. The review focuses on increasing events of neuropathy associated with immunecheckpoint inhibitors, which is one of the rare neurological irAEs, therefore, the least reviewed. The severity and distribution of neurologic toxicities are important deciding factors for its management (CNS vs. PNS), although there is no strong evidence for patients treated with ICIs are specifically affected by the use of immune-modulating interventions. Furthermore, the review discusses on pathophysiology, incidence, clinical presentation, diagnosis, and management of neuropathies as a result of ICIs. Early administration of high-dose corticosteroids is the main management of neuropathies especially for grade 3 or 4 irAEs initial cessation of ICI therapy with continued steroids which are necessary. However, the optimal duration of ICI therapy to minimize the risk of toxicity should be kept under consideration.
\end{abstract}

\section{Keywords}

Immune-Related Adverse Events, Immune Checkpoint Inhibitors, Nivolumab, Ipilimumab, Lung Cancer, Melanoma

\section{Introduction}

The specific focus of immune target cells has proved as a revolutionary approach for management of multiple malignancies modulating it into an important branch in the field of Medical Oncology. The upregulation of T-cells pathways 
directed for enhanced initiation of immune directed antitumor responses with the focus on immune target cells is vital for the augmentation of immune directed cancer cell attack. The reinforcement of these immune cells has henceforth shown promising results for the recent and future avenues [1]. Considering its results and responses, food and drug administration (FDA) had already approved ICI for metastatic melanoma, non-small cell lung cancer (NSCLC), renal cell carcinoma (RCC), bladder cancer, head and neck cancer, and Hodgkin's lymphoma, etc. (Table 1). In 2011, Ipilimumab, a cytotoxic T lymphocyte associated antigen 4 (CTLA4) targeting antibody was approved for advanced melanoma [2]. Further in 2014, approval of Nivolumab and pembrolizumab, monoclonal antibodies directed against the programed cell death 1 (PD-1), was witnessed. Following in 2016-2017, further approval of anti-PD-1 ligand (PD-L1) agents was witnessed [3]. Nivolumab was approved for metastatic NSCLC, RCC, Hodgkin's lymphoma, metastatic melanoma, and along with Pembrolizumab for metastatic melanoma, lung cancer and metastatic head and neck cancer. Later, Atezolizumab was approved for urothelial carcinoma.

Although through immune activation mechanism, it proves to be a very efficient therapy, concurrently significant immune-related adverse events (IRAEs) pose as a major drawback for the same. Generally termed as IRAEs, it almost affects multiorgan with a wide range of toxicities. Studies for the toxicities are mostly focused on colitis, hepatitis, pneumonitis and other IRAEs whereas there is much less emphasis on peripheral neuropathy [4]. Neuropathies though are rare, are increasing in incidence in recent interventions with ICI. With the above on focus, in this study, we aim to review the literature about IRAE associated neuropathies.

Table 1. FDA approved immune checkpoint inhibitors.

\begin{tabular}{|c|c|}
\hline $\begin{array}{l}\text { Anti-CTLA4 mAbs } \\
\text { Ipilimumab }\end{array}$ & Stage III and Metastatic melanoma \\
\hline $\begin{array}{l}\text { Anti-PD-L1 mAbs } \\
\text { Atezolizumab }\end{array}$ & $\begin{array}{l}\text { 2nd line regiment for metastatic nonsmall-cell lung cancer Advanced or } \\
\text { metastatic urothelial carcinoma }\end{array}$ \\
\hline Avelumab & $\begin{array}{l}\text { Advanced or metastatic urothelial carcinoma Metastatic Merkel cell } \\
\text { carcinoma }\end{array}$ \\
\hline Durvalumab & Advanced or metastatic urothelial carcinoma \\
\hline & $\begin{array}{l}\text { Metastatic melanoma } \\
\text { 2nd line metastatic regiment of nonsmall-cell lung cancer }\end{array}$ \\
\hline Anti-PD-1 mAbs & 2nd line regiment of metastatic renal cell carcinoma \\
\hline Nivolumab & $\begin{array}{l}\text { Refractory classical Hodgkin lymphoma } \\
\text { Recurrent or metastatic squamous cell carcinoma of the head and neck } \\
\text { Advanced or metastatic urothelial carcinoma }\end{array}$ \\
\hline & $\begin{array}{l}\text { Metastatic melanoma } \\
1 \text { st and } 2 \text { nd line regiment for metastatic nonsmall-cell lung cancer }\end{array}$ \\
\hline Pembrolizumab & $\begin{array}{l}\text { Advanced or metastatic renal cell carcinoma Refractory classical } \\
\text { Hodgkin lymphoma MSI-high or MMR-deficient metastatic solid tumors } \\
\text { Advanced or metastatic urothelial carcinoma }\end{array}$ \\
\hline
\end{tabular}




\section{CTLA-4 and PD-1 Pathways}

The cancer associated genetic mutations results various tumor associated antigen expression on cancer cells. The Major Histocompatibility Complex (MHC) presents the tumor associated molecules to the Antigen Presenting Cells (APC) on their surface for the T-cell receptor (TCR) recognition as seen in (Figure 1). Henceforth, multiple "non self" tumor-associated antigens induces series of attack on all tumor cells expressing these antigens [5].

However, CTLA-4 is associated with the inhibition of $\mathrm{T}$ cell activation and clonal expansion, through targeting CTLA-4 active blocking mechanism, helps to maintain further activation and proliferation of effector $\mathrm{T}$ cells ultimately enhancing the tumor immune responses [6]. Unfortunately it also results in inhibition of normal physiological $\mathrm{T}$ cell-mediated immunosuppression, thus leading to immune related toxic effects.

Studies show multiple malignancies with PD-1 expression on its tumor-infiltrating lymphocytes. The expression of PD-L1 expression is known to inhibit the T-cell antitumor response which is a major factor for cancer progress [7] [8]. It is noticed the tumor PD-L1 expression to be directly proportional to active tumor immune microenvironment [9]. The long duration of exposure of these antigen could lead to exhaustion or anergy. The focus on the PD-1 blockade may reverse anergy of tumor-specific T cells.

\section{Immune Check Point Inhibitors and IRAEs}

Immune checkpoints active blockades, in the maintenance of self-tolerance can have a huge impact on immunological tolerance, which could eventually

\section{Blocking CTLA-4 and PD-1 pathways}

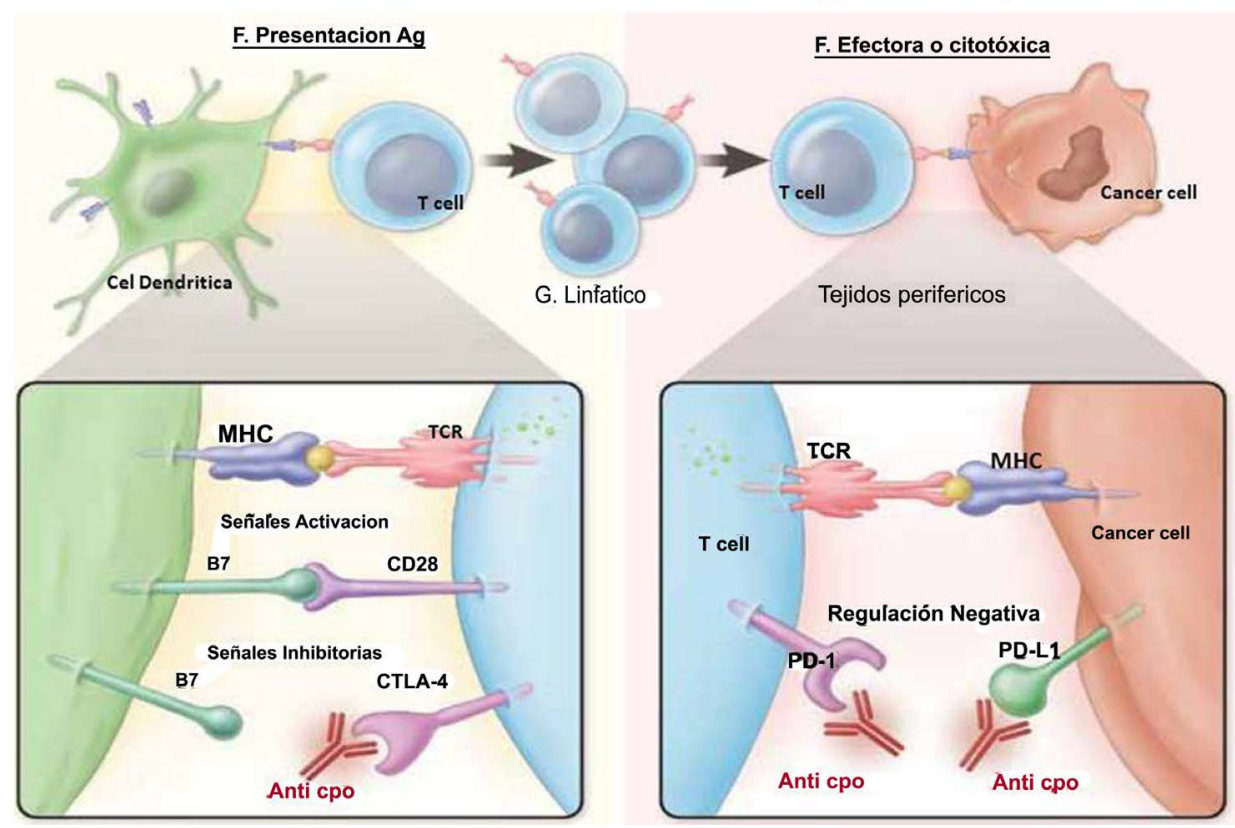

Figure 1. CTLA4 and PD1 pathway [14]. 
create autoimmune or inflammatory side effects, termed "immune-related adverse events" [10] [11] [12].

Commonly witnessed CTLA4 and PD-1 and PD-L1 adverse effect profiles [10] are fatigue, rash, pruritus and diarrhea. It is noticed PD1 and PDL1 have lower risk of toxicities while compared to the CTLA4. As irAEs can affect nearly every organ in association with checkpoint inhibitors, an early-onset and late-onset recognition of the toxic effects with effective mechanism of identification and management are very crucial for an optimal and efficient application of these immunotherapies [13].

\section{Neuropathies}

Despite the efficacy ICI therapy is associated with wide spectrum of immune-related adverse events (irAEs), whereas common adverse reactions are rash, colitis, hepatitis, endocrinopathies, and pneumonitis. The neurological side effects are rare such as immune polyneuropathies, Guillain Barré syndrome, myasthenia gravis, posterior reversible encephalopathy syndrome, aseptic meningitis, enteric neuropathy, transverse myelitis and immune encephalitis, etc. [15].

Among the neurotoxic events, there are cases of ICIs intervention with mild peripheral neuropathies and multiple inflammatory conditions such as meningoradiculitis or meningoradiculonevitis [16] [17]. The case of demyelinating polyradiculoneuropathy is approximately estimated to be in the range of $0.1 \%$ $0.2 \%$ with anti-PD1 and/or anti-CTLA4 agents intervention [18]. Studies show neuropathies occurring in fewer than 1\%. [19] While introduced with neuropathies, it always requires systematic evaluation of the patients with a proper history of previous treatment and complication while under intervention. Furthermore patients with acute or subacute sensory-motor symptoms sometimes are associated with cranial nerve involvement or dysautonomia [20] [21] [22].

The neurologic toxic events are diagnosed through, cerebrospinal fluid (CSF) analysis where reports of elevated protein levels, lymphocytosis (around 10 - 15 cells) and normal glucose level are expected. There are studies with oligoclonal bands in the CSF being observed with a systemic immune activation and high CSF cellularity. The brain and spinal MRI are suggested for excluding CNS and meningeal involvement [23] [24]. For the diagnosis of nerve demyelination electromyography with nerve conduction could be an option.

Regarding the pathogenesis, very less is known for neurological irAEs. It is suggested that checkpoint inhibition could be caused precipitating an underlying autoimmune disorders. For example, ipilimumab can induce myasthenia gravis, disease associated with T-cell-mediated production of acetylcholine receptor antibodies [24].

\section{Incidence of Neuropathy Associated ICIs in Patients with Cancer}

Reports on the neuropathy associated with ICI therapies are not much identi- 
fied. A. Ribas et al. mentioned on a randomized phase 2 trial study after two or more ipilimumab doses and, if BRAFV600 mutant-positive, previous treatment with a BRAF or MEK inhibitor or both for assessing the efficacy and safety of two pembrolizumab doses versus investigator-choice chemotherapy in patients with ipilimumab-refractory melanoma had, pembrolizumab $2 \mathrm{mg} / \mathrm{kg}$ or $10 \mathrm{mg} / \mathrm{kg}$ every 3 weeks or investigator-choice chemotherapy (paclitaxel plus carboplatin, paclitaxel, carboplatin, dacarbazine, or oral temozolomide). The result showed a single case of peripheral neuropathy among 178 with the $2 \mathrm{mg} / \mathrm{kg}$ intervention and 2 cases and 1 among 179 patients on $10 \mathrm{mg} / \mathrm{kg}$ intervention [1].

James et al. searched a Global Pharmacovigilance and Epidemiology database for neurologic irAEs reported over an 8-year period in patients with advanced melanoma receiving nivolumab with or without ipilimumab with advanced melanoma stated 22 neuropathy cases among 3763 patients [18].

A metanalysis of randomized controlled trials by Tomohiro et al. with the inclusion criteria of; phase II and III trials in patients with cancer; random assignment of participants to treatment with single-agent PD-1/PD-L1 inhibitor or chemotherapy; and reporting of events or event rate and sample size for any all-grade (1 - 4) or high-grade (3 - 4) AEs, individual all- or high-grade AEs, treatment discontinuation for AEs, or treatment-related deaths. The result with the comparison with chemotherapy, the intervention with PD1/PDL1 inhibitor had six trials $(1.2 \%)$ of all grade sensory neuropathy and five trials $(0.8 \%)$ cases of high grade sensory neuropathy among 3450 patients [25].

Paolo et al. on a randomized, double-blind, multicenter, phase 3 study done in 87 centers in 21 countries worldwide reported a phase 3 trial comparing the benefit-risk of ipilimumab $10 \mathrm{mg} / \mathrm{kg}$ versus $3 \mathrm{mg} / \mathrm{kg}$. This study included patients with untreated or previously treated unresectable stage III or IV melanoma, without previous treatment with BRAF inhibitors or immune checkpoint inhibitors, were randomly assigned (1:1) with an interactive voice response system by the permuted block method using block size 4 to ipilimumab $10 \mathrm{mg} / \mathrm{kg}$ or $3 \mathrm{mg} / \mathrm{kg}$, administered by intravenous infusion for 90 min every 3 weeks for four doses. Results showed three cases of grade three-peripheral motor and sensory neuropathy on Ipilimumab $10 \mathrm{mg} / \mathrm{kg}$ intervention among 364 patients.

Antonia, S. J., et al. on a multicenter, open-label, two-stage, multi-arm phase $1 / 2$ trial Grade 3 or 4 treatment-related peripheral neuropathy occurred in a single case with nivolumab plus ipilimumab arm [25] [26].

Weber JS et al. on randomized, open-label, phase 2 study, with patients from nine academic medical centers in the USA with eligible patients 18 years and above, had histologically confirmed unresectable stage III or stage IV melanoma, previously untreated or had progressed after no more than one previoussystemic therapy. With an Eastern Cooperative Oncology Group performance status of 0 or 1 ), patients were randomly assigned (1:1) to induction with intravenous nivolumab $3 \mathrm{mg} / \mathrm{kg}$ every 2 weeks for six doses followed by a planned switch to intravenous ipilimumab $3 \mathrm{mg} / \mathrm{kg}$ every 3 weeks for four doses, 


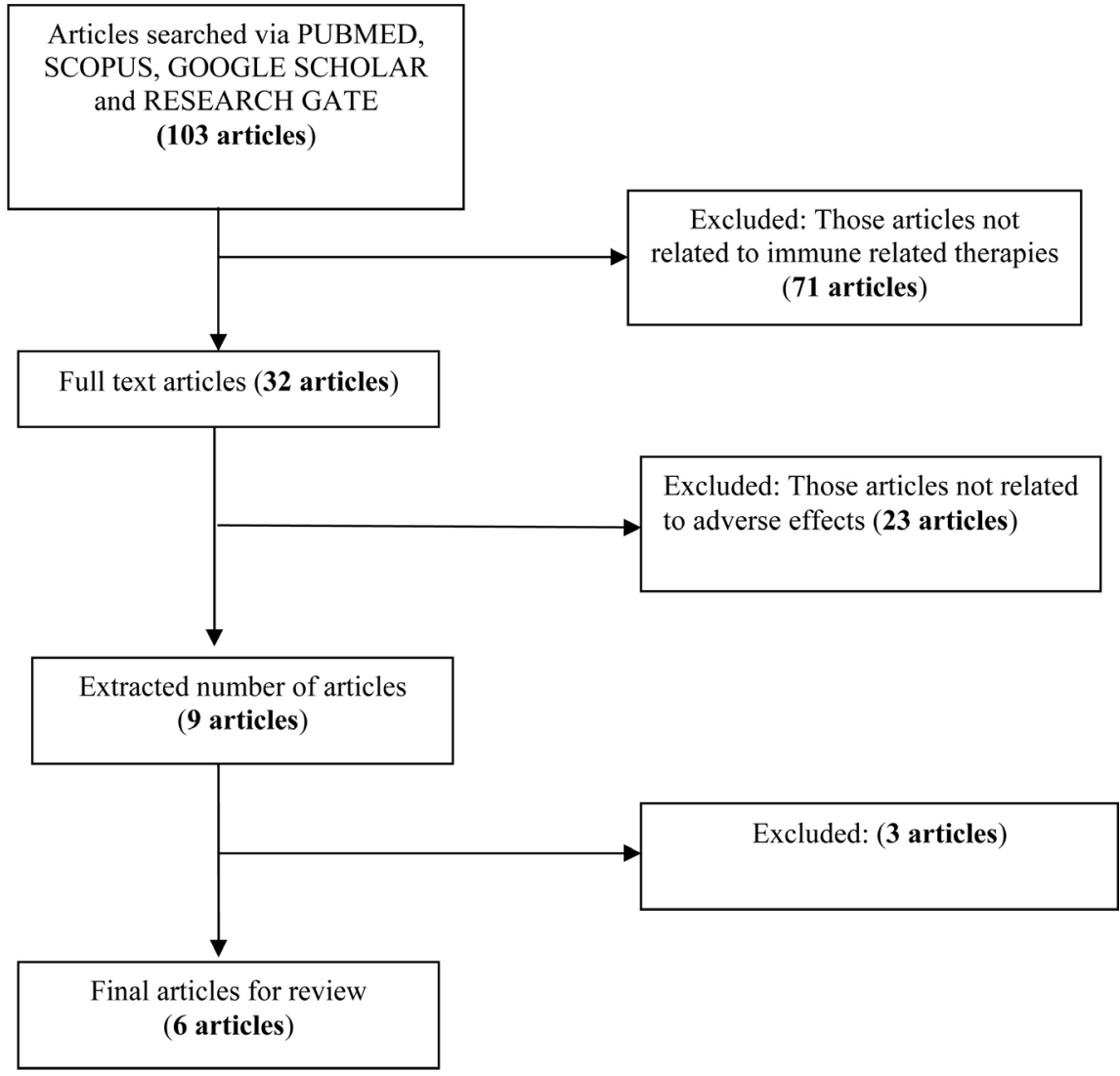

Figure 2. Flowchart showing the article selection process included in the review.

or the reverse sequence. The result showed Nivolumab followed by ipilimumab $(\mathrm{n}=68)$ a grade four demyelinating polyneuropathy among 1 patient [27]. Study processes are presented in Figure 2 and the selected study is summarized in $\mathrm{Ta}$ ble 2.

\section{Immune Related Neuropathy: Management}

The severity and distribution of neurologic toxicities are important factors for deciding its management (CNS vs. PNS). Although there are no strong evidence of patients treated with ICIs are specifically affected by the use of immune-modulating interventions [28] [29]. Still these adverse effects could result in the severe complications, so early detection and intervention are vital. There are wide range of studies indicating corticosteroids as the first line of treatment for ICI-related neurologic irAEs [24] [30] [31] [32].

According to the intensity of severity, immune related adverse effects are graded 1 to 4 . For the symptomatic grade 1 - 2 adverse effects, corticosteroids $(0.5-1 \mathrm{mg} / \mathrm{kg} /$ day of prednisolone equivalent) are recommended after the cessation of ICI. If no obvious improvement after 7 - 10 days follows up, it is to be considered and managed as a grade 3 adverse event.

For the grade 3 - 4 events, an immediate hospitalization with systemic corticosteroid therapy ( $1 \mathrm{mg} / \mathrm{kg} /$ day of prednisolone equivalent) are advised. 
Table 2. Summary of adverse effects of the included study.

\begin{tabular}{|c|c|c|c|c|}
\hline $\begin{array}{c}\text { Source and } \\
\text { publication year }\end{array}$ & Year of Study & Study Design & No. of patients & $\begin{array}{l}\text { No. of neuropathic } \\
\text { incidence }\end{array}$ \\
\hline Ribas A. et al. & 2015 & randomized phase 2 trial & $\begin{array}{c}\mathrm{N}=178(\text { pembrolizumab } 2 \mathrm{mg} / \mathrm{kg}) \\
\mathrm{N}=179(\text { pembrolizumab } 10 \mathrm{mg} / \mathrm{kg})\end{array}$ & $\begin{array}{l}\mathrm{N}=2 \\
\mathrm{~N}=1\end{array}$ \\
\hline James et al. & 2017 & Review & $\begin{aligned} \mathrm{N}= & 3763 \text { (nivolumab with or } \\
& \text { without ipilimumab) }\end{aligned}$ & $\mathrm{N}=22$ \\
\hline Tomohiro et al. & 2017 & randomized controlled trials-metanalysis & $\begin{aligned} \mathrm{N}= & 3450 \text { (single-agent } \mathrm{PD}-1 / \mathrm{PD}-\mathrm{L} 1 \\
& \text { inhibitor or chemotherapy) }\end{aligned}$ & $\mathrm{N}=6$ \\
\hline Paolo et. al & 2017 & $\begin{array}{l}\text { randomized, double-blind, multicenter, } \\
\text { phase } 3 \text { study }\end{array}$ & $\mathrm{N}=364($ ipilimumab $10 \mathrm{mg} / \mathrm{kg}$ or $3 \mathrm{mg} / \mathrm{kg})$ & $\mathrm{N}=3$ \\
\hline Antonia et al. & 2016 & $\begin{array}{l}\text { Multicenter, open-label, two-stage, } \\
\text { multi-arm phase } 1 / 2 \text { trial. }\end{array}$ & $\begin{array}{c}\mathrm{N}=54 \text { (nivolumab } 3 \mathrm{mg} / \mathrm{kg} \text { plus } \\
\text { ipilimumab } 1 \mathrm{mg} / \mathrm{kg} \text { ) }\end{array}$ & $\mathrm{N}=1$ \\
\hline Weber JS et. al & 2015 & randomized, open-label, phase 2 study, & $\mathrm{N}=68$ (Nivolumab followed by ipilimumab) & $\mathrm{N}=1$ \\
\hline
\end{tabular}

Initially a bolus short-course intravenous corticosteroids are preferred (500 $\mathrm{mg} /$ day for 3 days, followed by $1 \mathrm{mg} / \mathrm{kg} /$ day of prednisolone equivalent) with further evaluation for the improvement of the toxicity. Further medications according to the type of toxicity are indicated such as, anticholinesterase inhibitors for myasthenia gravis, empiric anti-biotic and/or antiviral treatment for encephalitis et al. it is to be noted that with the improvement of the patient's condition corticosteroids are usually tapered over a period of at least 2 months, with a regular follow-up, until completion of the regiment.

The first line corticosteroid non-responsive or partially responsive patients, alternatives such as IVIg, [20] plasmapheresis (usually 5 - 6 sessions], [33] anti-TNF-alpha antibodies (e.g. infliximab], [34] mycofenolatemofetyl [35] and rituximab. [34] These intervention showed few but positive results. Hence, it could be considered according to the type and severity of irAE, although proper care, its relative risks and benefit are to be considered. The immunosuppressants such as Methotrexate and cyclophosphamide also showed efficacy in other dysimmune neurologic disorders. In treatment-refractory patients, alternative immunosuppressive agents are rarely used with toxicity basis involving other organs, proteasome inhibitors (bortezomib), calcineurin inhibitors tacrolimusor IL-17 blockers could be considered.

\section{Discussion}

With the rapid regression of tumors, checkpoint blockade has its striking with enhanced patients survival among multiple solid malignant tumors. Although Immune checkpoint inhibitors show promising results there are high possibility of auto-immune disorders. These disorders are termed IRAEs, and are mostly associated with monoclonal antibodies.

As the medical field advances bringing together multiple faculties the management of neurotoxic events it is essential for oncologists and neurologists to work together. Recent studies regarding the incidence of neurotoxicity are 
mostly focused on GBS, meningism, encephalopathy, etc., whereas specific studies regarding neuropathy are minimal. Therefore, we conducted the review with the focus on increase in incidence of neuropathies occurring under immune checkpoint inhibitors in cancer patients.

The increasing incidence of ICI intervention necessitates a frequent interaction among oncologists, immunologists, neurologists for an early detection with proper characterization of immune induced neurotoxicity. Further a rapid management is advised for Anti-CTLA-4 and anti-PD-1/PD-L1 antibodies which are usually reversible. The increase in incidence of severe neurologic toxicity has brought to the light an important question for future oncology trials and clinical practice of these checkpoint inhibitors.

Early and late neurotoxic events require a complete neurological examination and monitoring. It is obvious that the implementations of ICIs are increasing for tumor management following years. Therefore, it is necessary to evaluate neurologic manifestation to detect the potential neuropathies.

For the management prospects, CSF analysis with a demyelinating and/ or an asymmetrical pattern on electroneuromyography is very favorable. Although, still a standard protocol is a necessity for neurological AEs, studies have shown improvements only after the discontinuation of the ICIs. Oral prednisone around 1 $\mathrm{mg} / \mathrm{kg} /$ day is a common initial therapy. Furthermore there is a neurological AEs management algorithm being proposed [15] [36] [37]. However, further studies are necessary for specific intervention along with dose and duration of application. There are other interventions such as immuno-suppressive agents or plasmaphaeres is under evaluation.

ICI after neurological recovery is still under consideration which requires a careful analysis. We suggest further trials assessing the progress of immune disorders to be studied after recontinuing ICI would be vital with regards to its hazards.

\section{Conclusions}

With much advancement immune checkpoint inhibitors show a promising, a future perspective in the field of oncology and are increasingly being indicated for first and second line intervention. Unfortunately, there are immune associated toxicities alongside. The upregulation of T-cell activity eventually leads to immune tolerance disruption with autoimmune syndromes. Although it is noticed that irAEs are much lower with PD-1 inhibitors compared with CTLA4 inhibitors, the concern for the toxicities can be severe and cannot be ignored.

Among the toxicities, neurological-irAEs are rare but often can be severe. Multidisciplinary approach oriented management with early bolus corticosteroids with synchronic supportive care required. However, proper recognition, evaluation and pathophysiology of ICI induced neurotoxicities are still a challenge due to difficulty in identifying biomarkers susceptible to irAEs. This heightens the complexity for optimized management for immune related ad- 
verse events. Therefore, certain studies have stated that underlying autoimmune disorders or patients with neurologic manifestations prior to ICI intervention should not be denied access to ICI [23] [38] [39] [40]. Finally, we hereby notify there is a need for further research for the management of neurologic irAEs aiming for a much enhanced management strategy.

\section{Limitation}

We would like to notify that our study suffered from several limitations. First the incidence of neuropathies was extracted from large clinical trials. Unfortunately, some trials were poorly characterized, with limited explorations, which could lead to mis-interpretation. Therefore, further studies for the understanding of the neuro-logical AEs especially neuropathies would help to provide optimal management.

\section{Acknowledgements}

We would like to thank the faculty members of Department of Oncology, Zhongda Hospital Affiliated to Southeast University for their coordination. Further, we express our gratitude towards Dr. Sundar Karki for his guidance.

\section{Conflicts of Interest}

The authors declare no conflicts of interest regarding the publication of this paper.

\section{References}

[1] Ribas, A. (2015) Releasing the Brakes on Cancer Immunotherapy. The New England Journal of Medicine, 373, 1490-1492. https://doi.org/10.1056/NEJMp1510079

[2] Tosti, G., Cocorocchio, E. and Pennacchioli, E. (2013) Anti-Cytotoxic T Lymphocyte Antigen-4 Antibodies in Melanoma. Clinical, Cosmetic and Investigational Dermatology, 6, 245. https://doi.org/10.2147/CCID.S24246

[3] Psimaras, D. (2018) Neuromuscular Complications of Immune Checkpoint Inhibitors. La Presse Médicale, 47, 253-259. https://doi.org/10.1016/j.lpm.2018.10.009

[4] Touat, M., Talmasov, D., Ricard, D. and Psimaras, D. (2017) Neurological Toxicities Associated with Immune-Checkpoint Inhibitors. Current Opinion in Neurology, 30, 659-668. https://doi.org/10.1097/WCO.0000000000000503

[5] Chen, D.S. and Mellman, I. (2013) Oncology Meets Immunology: The Cancer-Immunity Cycle. Immunity, 39, 1-10.

https://doi.org/10.1016/j.immuni.2013.07.012

[6] Pardoll, D.M. (2012) The Blockade of Immune Checkpoints in Cancer Immunotherapy. Nature Reviews Cancer, 12, 252. https://doi.org/10.1038/nrc3239

[7] Umezu, D., Okada, N., Sakoda, Y., Adachi, K., Ojima, T., Yamaue, H., et al. (2019) Inhibitory Functions of PD-L1 and PD-L2 in the Regulation of Anti-Tumor Immunity in Murine Tumor Microenvironment. Cancer Immunology, Immunotherapy, 68, 201-211. https://doi.org/10.1007/s00262-018-2263-4

[8] Ascierto, P.A., Del Vecchio, M., Robert, C., Mackiewicz, A., Chiarion-Sileni, V., Arance, A., et al. (2017) Ipilimumab $10 \mathrm{mg} / \mathrm{kg}$ versus Ipilimumab $3 \mathrm{mg} / \mathrm{kg}$ in Pa- 
tients with Unresectable or Metastatic Melanoma: A Randomised, Double-Blind, Multicentre, Phase 3 Trial. The Lancet Oncology, 18, 611-622. https://doi.org/10.1016/S1470-2045(17)30231-0

[9] Pitt, J.M., Vétizou, M., Daillère, R., Roberti, M.P., Yamazaki, T., Routy, B., et al. (2016) Resistance Mechanisms to Immune-Checkpoint Blockade in Cancer: Tumor-Intrinsic and -Extrinsic Factors. Immunity, 44, 1255-1269. https://doi.org/10.1016/j.immuni.2016.06.001

[10] Gangadhar, T.C. and Vonderheide, R.H. (2014) Mitigating the Toxic Effects of Anticancer Immunotherapy. Nature Reviews Clinical Oncology, 11, 91. https://doi.org/10.1038/nrclinonc.2013.245

[11] Michot, J., Bigenwald, C., Champiat, S., Collins, M., Carbonnel, F., Postel-Vinay, S., et al. (2016) Immune-Related Adverse Events with Immune Checkpoint Blockade: A Comprehensive Review. European Journal of Cancer, 54, 139-148. https://doi.org/10.1016/j.ejca.2015.11.016

[12] Buchbinder, E.I. and Desai, A. (2016) CTLA-4 and PD-1 Pathways: Similarities, Differences, and Implications of Their Inhibition. American Journal of Clinical Oncology, 39, 98. https://doi.org/10.1097/COC.0000000000000239

[13] Varricchi, G., Galdiero, M.R., Marone, G., Criscuolo, G., Triassi, M., Bonaduce, D., et al. (2017) Cardiotoxicity of Immune Checkpoint Inhibitors. ESMO Open, 2, Article ID: 000247. https://doi.org/10.1136/esmoopen-2017-000247

[14] de Cos Escuín, J.S. (2017) Nueva inmunoterapia y cáncer de pulmón. Archivos de Bronconeumología, 53, 682-687. https://doi.org/10.1016/j.arbres.2017.06.016

[15] Hottinger, A.F. (2016) Neurologic Complications of Immune Checkpoint Inhibitors. Current Opinion in Neurology, 29, 806-812. https://doi.org/10.1097/WCO.0000000000000391

[16] Bompaire, F., Mateus, C., Taillia, H., De Greslan, T., Lahutte, M., Sallansonnet-Froment, M., et al. (2012) Severe Meningo-Radiculo-Nevritis Associated with Ipilimumab. Investigational New Drugs, 30, 2407-2410.

https://doi.org/10.1007/s10637-011-9787-1

[17] Manousakis, G., Koch, J., Sommerville, R.B., El-Dokla, A., Harms, M.B., Al-Lozi, M.T., et al. (2013) Multifocal Radiculoneuropathy during Ipilimumab Treatment of Melanoma. Muscle \& Nerve, 48, 440-444. https://doi.org/10.1002/mus.23830

[18] Larkin, J., Chmielowski, B., Lao, C.D., Hodi, F.S., Sharfman, W., Weber, J., et al. (2017) Neurologic Serious Adverse Events Associated with Nivolumab plus Ipilimumab or Nivolumab Alone in Advanced Melanoma, Including a Case Series of Encephalitis. The Oncologist, 22, 709-718. https://doi.org/10.1634/theoncologist.2016-0487

[19] Dalakas, M.C. (2018) Neurological Complications of Immune Checkpoint Inhibitors: What Happens When You “Take the Brakes off” the Immune System. Therapeutic Advances in Neurological Disorders, 11, Article ID: 1756286418799864. https://doi.org/10.1177/1756286418799864

[20] Liao, B., Shroff, S., Kamiya-Matsuoka, C. and Tummala, S. (2014) Atypical Neurological Complications of Ipilimumab Therapy in Patients with Metastatic Melanoma. Neuro-Oncology, 16, 589-593. https://doi.org/10.1093/neuonc/nou001

[21] Gaudy-Marqueste, C., Monestier, S., Franques, J., Cantais, E., Richard, M.-A. and Grob, J.-J. (2013) A Severe Case of Ipilimumab-Induced Guillain-Barré Syndrome Revealed by an Occlusive Enteric Neuropathy: A Differential Diagnosis for Ipilimumab-Induced Colitis. Journal of Immunotherapy, 36, 77-78.

https://doi.org/10.1097/CJI.0b013e31827807dd 
[22] Gu, Y., Menzies, A.M., Long, G.V., Fernando, S. and Herkes, G. (2017) Immune Mediated Neuropathy Following Checkpoint Immunotherapy. Journal of Clinical Neuroscience, 45, 14-17. https://doi.org/10.1016/j.jocn.2017.07.014

[23] Boisseau, W., Touat, M., Berzero, G., Savatovsky, J., Marabelle, A., Touitou, V., et al. (2017) Safety of Treatment with Nivolumab after Ipilimumab-Related Meningoradiculitis and Bilateral Optic Neuropathy. European Journal of Cancer, 83, 28-31. https://doi.org/10.1016/j.ejca.2017.05.036

[24] Wilgenhof, S. and Neyns, B. (2011) Anti-CTLA-4 Antibody-Induced Guillain-Barré Syndrome in a Melanoma Patient. Annals of Oncology, 22, 991-993. https://doi.org/10.1093/annonc/mdr028

[25] Nishijima, T.F., Shachar, S.S., Nyrop, K.A. and Muss, H.B. (2017) Safety and Tolerability of PD-1/PD-L1 Inhibitors Compared with Chemotherapy in Patients with Advanced Cancer: A Meta-Analysis. The Oncologist, 22, 470-479. https://doi.org/10.1634/theoncologist.2016-0419

[26] Antonia, S.J., López-Martin, J.A., Bendell, J., Ott, P.A., Taylor, M., Eder, J.P., et al. (2016) Nivolumab Alone and Nivolumab plus Ipilimumab in Recurrent Small-Cell Lung Cancer (CheckMate 032): A Multicentre, Open-Label, Phase 1/2 Trial. The Lancet Oncology, 17, 883-895. https://doi.org/10.1016/S1470-2045(16)30098-5

[27] Weber, J.S., Gibney, G., Sullivan, R.J., Sosman, J.A., Slingluff Jr., C.L., Lawrence, D.P., et al. (2016) Sequential Administration of Nivolumab and Ipilimumab with a Planned Switch in Patients with Advanced Melanoma (CheckMate 064): An Open-Label, Randomised, Phase 2 Trial. The Lancet Oncology, 17, 943-955. https://doi.org/10.1016/S1470-2045(16)30126-7

[28] Weber, J.S., Hodi, F.S., Wolchok, J.D., Topalian, S.L., Schadendorf, D., Larkin, J., et al. (2017) Safety Profile of Nivolumab Monotherapy: A Pooled Analysis of Patients with Advanced Melanoma. Journal of Clinical Oncology, 35, 785-792. https://doi.org/10.1200/JCO.2015.66.1389

[29] Horvat, T.Z., Adel, N.G., Dang, T.-O., Momtaz, P., Postow, M.A., Callahan, M.K., et al. (2015) Immune-Related Adverse Events, Need for Systemic Immunosuppression, and Effects on Survival and Time to Treatment Failure in Patients with Melanoma Treated with Ipilimumab at Memorial Sloan Kettering Cancer Center. Journal of Clinical Oncology, 33, 3193. https://doi.org/10.1200/JCO.2015.60.8448

[30] Zimmer, L., Goldinger, S.M., Hofmann, L., Loquai, C., Ugurel, S., Thomas, I., et al. (2016) Neurological, Respiratory, Musculoskeletal, Cardiac and Ocular Side-Effects of Anti-PD-1 Therapy. European Journal of Cancer, 60, 210-225. https://doi.org/10.1016/j.ejca.2016.02.024

[31] de Maleissye, M.-F., Nicolas, G. and Saiag, P. (2016) Pembrolizumab-Induced Demyelinating Polyradiculoneuropathy. New England Journal of Medicine, 375, 296-297. https://doi.org/10.1056/NEJMc1515584

[32] Tchapyjnikov, D. and Borst, A.J. (2017) Immune-Related Neurological Symptoms in an Adolescent Patient Receiving the Checkpoint Inhibitor Nivolumab. Journal of Immunotherapy, 40, 286-288. https://doi.org/10.1097/CJI.0000000000000177

[33] Vallet, H., Gaillet, A., Weiss, N., Vanhaecke, C., Saheb, S., Touitou, V., et al. (2016) Pembrolizumab-Induced Necrotic Myositis in a Patient with Metastatic Melanoma. Annals of Oncology, 27, 1352-1353. https://doi.org/10.1093/annonc/mdw126

[34] Pushkarevskaya, A., Neuberger, U., Dimitrakopoulou-Strauss, A., Enk, A. and Hassel, J.C. (2017) Severe Ocular Myositis after Ipilimumab Treatment for Melanoma: A Report of 2 Cases. Journal of Immunotherapy, 40, 282-285. https://doi.org/10.1097/CJI.0000000000000178 
[35] Williams, T.J., Benavides, D.R., Patrice, K.-A., Dalmau, J.O., De Ávila, A.L.R., Le, D.T., et al. (2016) Association of Autoimmune Encephalitis with Combined Immune Checkpoint Inhibitor Treatment for Metastatic Cancer. JAMA Neurology, 73, 928-933. https://doi.org/10.1001/jamaneurol.2016.1399

[36] Sivan, A., Corrales, L., Hubert, N., Williams, J.B., Aquino-Michaels, K., Earley, Z.M., et al. (2015) Commensal Bifidobacterium Promotes Antitumor Immunity and Facilitates anti-PD-L1 Efficacy. Science, 350, 1084-1089.

https://doi.org/10.1126/science.aac4255

[37] Postow, M.A., Chesney, J., Pavlick, A.C., Robert, C., Grossmann, K., McDermott, D., et al. (2015) Nivolumab and Ipilimumab versus Ipilimumab in Untreated Melanoma. New England Journal of Medicine, 372, 2006-2017. https://doi.org/10.1056/NEJMoa1414428

[38] Gutzmer, R., Koop, A., Meier, F., Hassel, J.C., Terheyden, P., Zimmer, L., et al. (2017) Programmed Cell Death Protein-1 (PD-1) Inhibitor Therapy in Patients with Advanced Melanoma and Preexisting Autoimmunity or Ipilimumab-Triggered Autoimmunity. European Journal of Cancer, 75, 24-32. https://doi.org/10.1016/j.ejca.2016.12.038

[39] Maul, L.V., Weichenthal, M., Kähler, K.C. and Hauschild, A. (2016) Successful Anti-PD-1 Antibody Treatment in a Metastatic Melanoma Patient with Known Severe Autoimmune Disease. Journal of Immunotherapy, 39, 188-190. https://doi.org/10.1097/CJI.0000000000000118

[40] Johnson, D.B., Sullivan, R.J., Ott, P.A., Carlino, M.S., Khushalani, N.I., Ye, F., et al. (2016) Ipilimumab Therapy in Patients with Advanced Melanoma and Preexisting Autoimmune Disorders. JAMA Oncology, 2, 234-240.

https://doi.org/10.1001/jamaoncol.2015.4368 